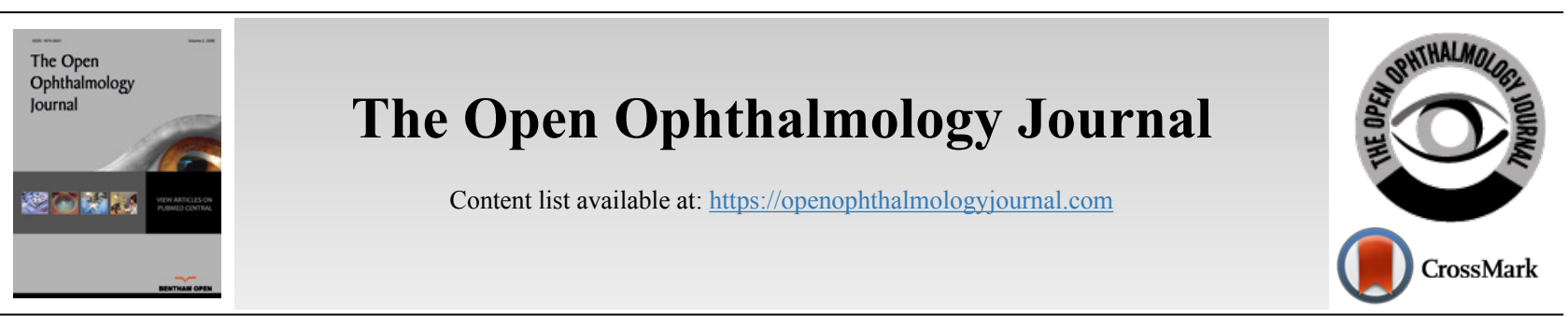

RESEARCH ARTICLE

\title{
Nocardia Endophthalmitis- Prophylactic Prevention with an Innovative Approach
}

\author{
Atul Kamath ${ }^{1, *}$, Aditi Pai ${ }^{2}$ and Jagadeesh K. Reddy ${ }^{3}$ \\ ${ }^{I}$ Department of Ophthalmology, Yenepoya University, Karnataka, India \\ ${ }^{2}$ Department of Ophthalmology, Maharaja Sayajirao University of Baroda, Gujarat, India \\ ${ }^{3}$ Department of Cornea, Sankara Eye Hospital, Coimbatore, India
}

\begin{abstract}
:
Background:

Nocardia is a common cause of endophthalmitis in southern India. It is an aggressive disease with a poor prognosis.

Objective:

This study was conducted using an amikacin antibiotic in the drip irrigation of balanced saline solution (BSS) during the surgery to prophylactically study the occurrence of Nocardia endophthalmitis and any subsequent toxic effects of the antibiotics used.

\section{Methods:}

Prospective study period was of 6 months, starting from July to December-2018. Preoperative and postoperative specular counts and macular thickness using Ocular Coherence Tomography (OCT) were compared with any incidence of Nocardia endophthalmitis. A total of 500 patients operated for manual SICS were randomly assigned into 2 groups. The first group of 250 patients received antibiotic amikacin added to the Balanced Saline Solution (BSS) irrigating solution throughout the course of the surgery. The second control group received no antibiotics. Manual SICS was performed on all 500 patients by a single surgeon and was found to be uneventful. Pre- and postoperative corneal endothelial cell density and mean macular thickness using OCT were taken and recorded of all the patients, respectively, and data obtained were statistically compared.

Results:

No incidence of Nocardia endophthalmitis among the cataract surgeries operated was found. There was no drug-related toxicity to the cornea or macula. Furthermore, no incidence of Nocardia endophthalmitis has been reported since 2018 after using antibiotics.

Conclusion:

A simple routine of adding amikacin in the drip prophylactically during the course of surgery helped us prevent Nocardia endophthalmitis with no side effects. Also, it will be an innovative technique that is economically feasible and effective in regions where Nocardia endophthalmitis is prevalent.
\end{abstract}

Keywords: Nocardia, Amikacin, Endophthalmitis, Specular microscopy, Macular OCT, Drip.

Article History Received: June 3, 2021

Revised: August 5, 2021

Accepted: September 21, 2021

\section{INTRODUCTION}

Nocardia is filamentous, gram-positive, weakly acid-fast bacteria, frequently found as soil saprophytes. Ocular nocardiosis has been associated with infectious keratitis, with the reported incidence varying from $0.3 \%$ to $4.2 \%$ of the cases

\footnotetext{
* Address correspondence to this author at the Department of Ophthalmology, Yenepoya University, India, Kausthubha, Chilimbi I Cross Hillgrove, Ladyhill Mangalore-575006, Karnataka, India; Tel: +91-9741474919;
}

E-mail: Dratulkamath29@Gmail.Com of microbial keratitis [1 - 3]. Postoperative infections after intraocular surgical procedures caused by Nocardia are rare but potentially sight-threatening ranging from deep corneal stromal infiltrates to exudates in the anterior chamber and scleral nodules, all of which have a poor prognosis [4]. Therefore, we conducted a study where we prophylactically added antibiotic amikacin to the irrigating solution used intraoperatively to study the occurrence of Nocardia endophthalmitis and any potential toxic effects of amikacin on the corneal endothelium 
as well as on the macula.

\section{MATERIALS AND METHODS}

\subsection{Study Design}

A prospective study involving 500 patients for 6 months, from July to December-2018, was conducted in our community-based sankara eye hospital, Coimbatore.

\subsection{Methodology}

People aged 50 years or above residing in the target area were enumerated for cataract evaluation in the screening camps, and people willing for surgery were brought to the base hospital for a comprehensive ophthalmic evaluation. The study received approval from the institutional review board, following which the study was carried out. Written informed consent was obtained from all participants before the commencement of examination and surgery.

The eligibility criteria included people diagnosed with cataracts during screening and willing for surgery, and the exclusion criteria included people with pre-existing and diagnosed corneal, macular, and retinal pathologies.

Examination procedures-A detailed evaluation which included recording relevant medical and ocular history was made. Snellen chart was used to record best-corrected visual acuity, after which, examination of the pupil under torchlight was done. Anterior segment was examined using a slit lamp. Eye drops containing $5 \%$ of phenylephrine and $1 \%$ of tropicamide were used to dilate the pupil of the patients and assess the grade of cataracts. $1 \%$ homatropine eye drops were used, in whom phenylephrine was contraindicated. LOCS II system was used for cataract grading in patients whose pupils dilated to $6 \mathrm{~mm}$ or more [5]. $+78 \mathrm{D}$ lens and indirect ophthalmoscope were used for stereoscopic evaluation of optic disc and fundus. Pre-operative corneal endothelial cell density and mean macular thickness using Ocular Coherence Tomography (OCT) were documented in all patients.

Diagnostic criteria were set according to the LOCS II system; patients with significant nuclear sclerosis with the nuclear colour of NC I or more were selected for surgery.

\subsection{Intervention}

A total of 500 patients operated for manual small incision cataract surgery were randomly assigned into 2 groups. The first group (group-1) of 250 patients received a $12.5 \mathrm{mg}$ dosage of antibiotic amikacin in the $500 \mathrm{ml}(0.025 \mathrm{mg}$ per $\mathrm{ml})$ of balanced saline solution (BSS) drip throughout the course of the surgery. The second control group (group-2) received no amikacin antibiotic in the drip during the procedure.

\subsection{Surgical Technique}

Manual small incision cataract surgery was performed on all 500 patients by a single surgeon. The first group (group-1) of 250 patients received a $12.5 \mathrm{mg}$ dosage of antibiotic amikacin (mikacin $^{\circledR}$, Aristo) in the $500 \mathrm{ml}(0.025 \mathrm{mg}$ per $\mathrm{ml})$ of balanced saline solution (BSS) drip throughout the course of the surgery. The second control group (group-2) received no amikacin antibiotic in the drip during the procedure. $3 \mathrm{cc}$ moxifloxacin $(0.5 \%)$ preservative-free eyedrops, Vigamox ${ }^{\circledR}$ (Alcon), was diluted with $7 \mathrm{cc}$ balanced salt solution, and $0.3 \mathrm{cc}$ to $0.4 \mathrm{cc}$ of this formulation was given intracamerally at the end of every surgery. All surgeries were uneventful. On postoperative day 1 , corneal endothelial cell density and mean macular thickness using OCT of all the patients were recorded and data obtained were statistically compared and interpreted.

\subsection{Outcome Definition}

The outcome considered at one day, one week, and onemonth postoperative was any severe vision loss with deep corneal stromal infiltrate and exudates in the anterior chamber and scleral nodules with confirmatory positive microscopy and culture for Nocardia species.

\subsection{Statistical Analysis}

Collected data were entered on a Microsoft excel sheet, and analysis was performed using statistical software MedCalc ver 12.2.1.0 (Ostend, Belgium). Online statistical calculators (https://www.allto.co.uk/tools/statistic-calculators) were used to calculate percentage confidence intervals. P-value $<0.05$ was considered statistically significant. OR with appropriate confidence intervals was computed for possible risk variables.

\section{RESULTS}

The study included 500 eyes of 500 patients who underwent manual small incision cataract surgery. In the first group (group-1) of 250 patients, 100 were male, and the remaining 150 were female patients. In the second group (group-2), 105 were male, and 145 were female patients.

Our tertiary center-based community eye hospital performed 34898, 32643, 34651, 34067, 33465 and 33108 surgeries in the years 2014, 2015, 2016, 2017, 2018, and 2019, respectively (Table $\mathbf{1}$ ).

Table 1. Total no. of cataract surgeries performed annually.

\begin{tabular}{|c|c|}
\hline Year & Total Surgeries \\
\hline 2014 & 34898 \\
\hline 2015 & 32643 \\
\hline 2016 & 34651 \\
\hline 2017 & 34067 \\
\hline 2018 & 33465 \\
\hline 2019 & 33108 \\
\hline
\end{tabular}

The incidences of endophthalmitis post-operatively over the last 6 years in our tertiary center were analysed. We started using antibiotic intracameral moxifloxacin in 2015 and noticed a drop in the incidence of endophthalmitis caused by coagulase-negative Staphylococcus sp., and a decline of more than $50 \%$ by 2019 was also observed. Among all those years, the incidence reported was less than $0.1 \%$, as shown in Table 2 .

In the year 2014 , it was observed that $2(18 \%)$ of 11 cases had Nocardia endophthalmitis. Similarly, 4 (44\%) of 9 cases in $2015,3(50 \%)$ of 6 cases in 2016, and $2(28 \%)$ of 7 cases in 2017 had Nocardia endophthalmitis (Table 3). 
Table 2. Total no. of cataract surgeries performed and incidence of endophthalmitis.

\begin{tabular}{|c|c|c|}
\hline Year & $\begin{array}{c}\text { Total Number of } \\
\text { Cataract Surgeries } \\
\text { Performed Annually }\end{array}$ & $\begin{array}{c}\text { Endophthalmitis (for the } \\
\text { Annually Performed Surgeries) }\end{array}$ \\
\hline 2014 & 34898 & $11(0.03 \%)$ \\
\hline 2015 & 32643 & $9(0.02 \%)$ \\
\hline 2016 & 34651 & $6(0.01 \%)$ \\
\hline 2017 & 34067 & $7(0.02 \%)$ \\
\hline 2018 & 33465 & $3(0.008 \%)$ \\
\hline 2019 & 33108 & $2(0.06 \%)$ \\
\hline
\end{tabular}

Table 3. Incidence of endophthalmitis with percentage of nocardia sp. Endophthalmitis.

\begin{tabular}{|c|c|c|}
\hline Year & $\begin{array}{c}\text { Endophthalmitis (for the } \\
\text { Annually Performed Surgeries) }\end{array}$ & $\begin{array}{c}\text { Nocardia sp. (for Total } \\
\text { endophthalmitis Cases) }\end{array}$ \\
\hline 2014 & $11(0.31 \%)$ & $2(18 \%)$ \\
\hline 2015 & $9(0.27 \%)$ & $4(44 \%)$ \\
\hline 2016 & $6(0.17 \%)$ & $3(50 \%)$ \\
\hline 2017 & $7(0.20 \%)$ & $2(28 \%)$ \\
\hline 2018 & $3(0.08 \%)$ & 0 \\
\hline 2019 & $2(0.09 \%)$ & 0 \\
\hline
\end{tabular}

Thus, $50 \%$ cases of endophthalmitis with poor prognosis were observed, and the percentage of Nocardia sp. induced endophthalmitis was significant. Hence, in 2016, antibiotic amikacin was started in the balanced saline solution drip for all the patients operated in our sankara eye hospital, Coimbatore. Since the introduction of antibiotic amikacin in the BSS, while performing the surgery, no incidence of Nocardia-related endophthalmitis in 2018 and 2019 was reported, which was as high as $50 \%$ in 2016. A significant decrease in the incidence of Nocardia sp. endophthalmitis following the introduction of intra-operative antibiotic amikacin in the irrigating drip was observed (Graph. 1).

We also wanted to rule out any potential toxicity to the cornea and macula using amikacin in a balanced salt solution drip. The mean corneal endothelial density among the two groups was compared. The mean corneal endothelial cell density in group 1 pre-operatively and post-operatively (day-1) was found to be $2550 \pm 200$ cells $/ \mathrm{mm}^{2}$ and $2525 \pm 200$ cells $/ \mathrm{mm}^{2}$, respectively. The mean corneal endothelial cell density in group-2 pre-operatively and post-operatively (day-1) was found to be $2500 \pm 200$ cells $/ \mathrm{mm}^{2}$ and $2495 \pm 200 \mathrm{cells} / \mathrm{mm}^{2}$, respectively (Graph. 2).

The mean macular thickness using OCT in group-1 was $235 \pm 15$ microns pre-operatively and $235 \pm 10$ microns postoperatively (day-1). Similarly, the mean macular OCT in group-2 pre-operatively and post-operatively (day-1) was $238 \pm 22$ microns and 238+17 (day-1), respectively (Graph. 3).

Comparing the difference in corneal endothelial cell density $(\mathrm{p}=1.137)$ and mean macular thickness using OCT $(\mathrm{p}=0.957)$, it was observed that readings of patients in groups 1 and 2 were not statistically significant. More importantly, no incidence of Nocardia endophthalmitis was reported among the 500 patients included in the study for a follow-up period of 1 month. After successfully starting intracameral moxifloxacin and amikacin in the BSS drip, a significant drop in the incidence of endophthalmitis and percentage of Nocardia sp. induced endophthalmitis was observed, respectively (Graph. 4).

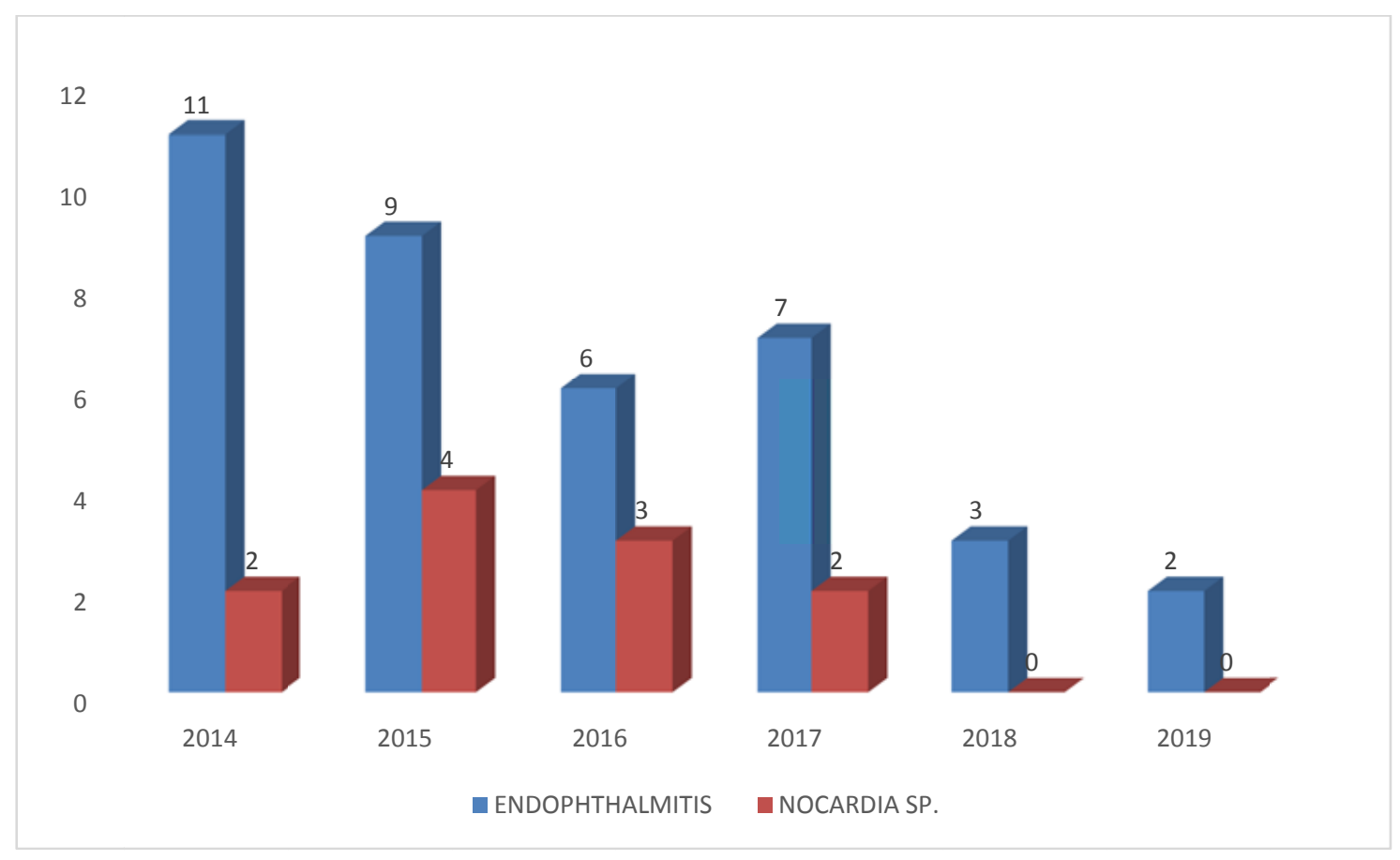

Graph (1). Annual endophthalmitis and nocardia sp. infective rate. 


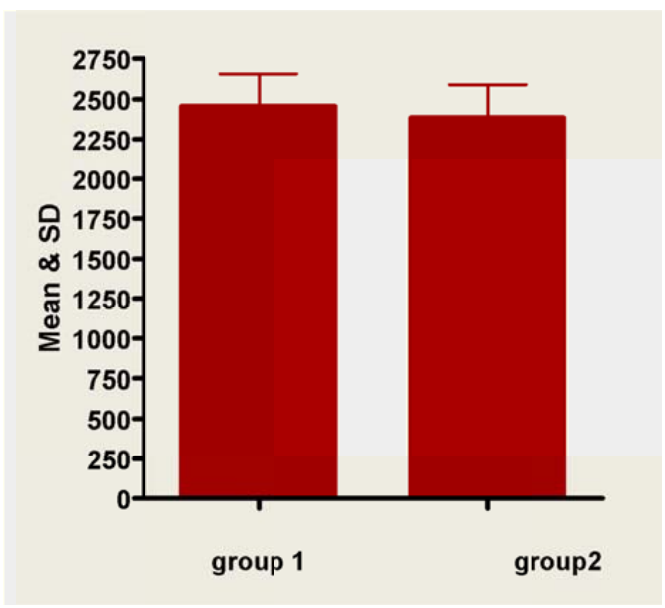

Graph (2). Mean corneal endothelial cell density in groups with and without amikacin. $(\mathrm{p}=1.137)$ insignificant difference $(\mathrm{p}>0.05$.

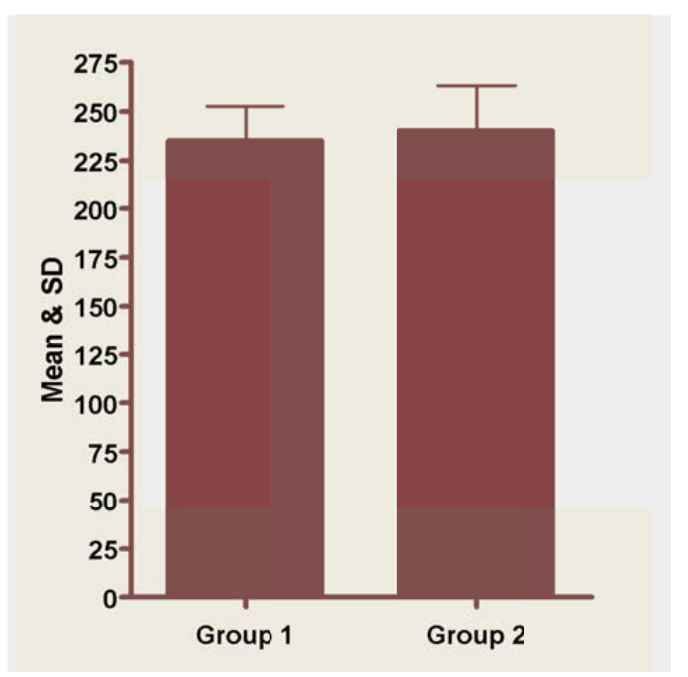

Graph (3). Mean macular thickness using oct in groups with and without amikacin. $(\mathrm{p}=0.957)$ insignificant difference $(\mathrm{p}>0.05)$.

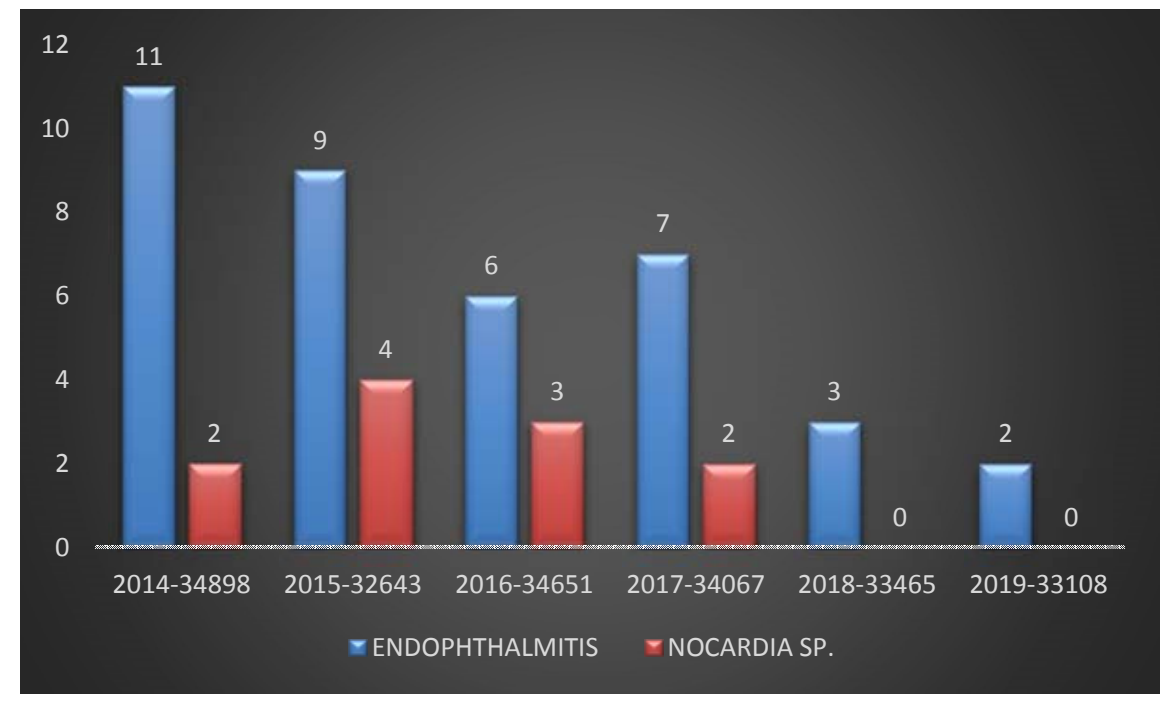

Graph (4). Annual incidence of endophthalmitis and percentage of nocardia sp. induced endophthalmitis. 


\section{DISCUSSION}

Prophylactic antibiotic moxifloxacin given intracamerally was found to be a safe and effective way to reduce endophthalmitis rates in patients of small-incision manual cataract surgery, and there was a 3.5-fold reduction in the overall endophthalmitis rate after routinely using intracameral moxifloxacin prophylactically [6]. After the application of intracameral moxifloxacin, there was a decline in the incidence of presumed infectious postoperative endophthalmitis [7]. We started using intracameral moxifloxacin in all our cases from 2015 and observed a significant decrease in the endophthalmitis cases caused by coagulase-negative Staphylococcus sp. in our center; however, the percentage of Nocardia induced endophthalmitis was very high, for which we started using amikacin in the irrigation drip system. Postoperative infections caused by Nocardia species are generally regarded as uncommon $[8,9]$. However, an unusually high rate $(16.8 \%)$ of postoperative infections caused by the organism has been found in South India [10]. Nocardia is found to be endemic in soil and dust [11] and may infect hospital spaces [12]. Considering this, we conducted a study on amikacin given intraoperatively during surgery in our tertiary center. The study reported no case of Nocardia endophthalmitis postoperatively, suggesting that the prophylactic use of intraoperative amikacin probably reduces the risk of developing this sight-threatening complication.

Trimethoprim-sulfamethoxazole and amikacin are effective drugs for treating Nocardia-related ocular infections, with sulfacetamide eyedrops also being used as an initial drug [13]. Also, the percentage of cases of endophthalmitis caused by Nocardia sp. over the last 5 years in our center drastically reduced from as high as $50 \%$ in 2016 to $0 \%$ in 2019 after introducing amikacin intra-operatively. Furthermore, it was noted that amikacin had negligible toxic effects on corneal endothelium and macula, further enhancing its efficacy to be used intraoperatively.

\section{CONCLUSION}

Our study showed a significant decrease in the incidence of coagulase-negative staphylococcus sp.induced endophthalmitis using intracameral moxifloxacin. In addition to intracameral moxifloxacin, zero infection rate by Nocardia endophthalmitis using antibiotic amikacin in the balanced saline irrigating solution during the course of the surgery was reported. In our study, surgery performed with amikacin antibiotic in the continuous irrigating drip resulted in better visual outcomes with nil Nocardia sp related infections. These conclusions are strengthened by the high volume of cases analyzed at a single hospital network over a comparatively short time frame. Considering the poor prognosis of Nocardia sp. associated endophthalmitis, prophylactic usage of amikacin was found to be ideal. No deleterious effect either on the corneal endothelial cell density or macular thickness was noted. As prevention is better than cure, a simple yet effective innovation that is economically feasible with nil economic burden is the usage of amikacin antibiotic in the balanced saline solution. This has very promising results in prophylactic control of Nocardiarelated postoperative infections in the places where Nocardia sp. induced endophthalmitis is prevalent.

\section{LIST OF ABBREVIATIONS}

\section{SICS $=$ Small Incision Cataract Surgery \\ OCT = Ocular Coherence Tomography \\ ETHICS APPROVAL AND CONSENT TO PARTI- CIPATE}

This study is approved by IEC. This committee works in accordance with ICH-GCP, Sankara eye hospital, Coimbatore ethical approval number-IEC/125/2018.

\section{HUMAN AND ANIMAL RIGHTS}

No animals were used for studies that are the basis of this study. All human procedures were conducted as per the Helsinki principles.

\section{CONSENT FOR PUBLICATION}

Written informed consent was obtained from all patients.

\section{AVAILABILITY OF DATA AND MATERIALS}

Not applicable.

\section{FUNDING}

None.

\section{CONFLICT OF INTEREST}

The author declares no conflict of interest, financial or otherwise.

\section{ACKNOWLEDGEMENTS}

Declared none.

\section{REFERENCES}

[1] Upadhyay MP, Karmacharya PC, Koirala S, et al. Epidemiologic characteristics, predisposing factors, and etiologic diagnosis of corneal ulceration in Nepal. Am J Ophthalmol 1991; 111(1): 92-9. [http://dx.doi.org/10.1016/S0002-9394(14)76903-X]

[PMID: 1985498]

[2] Garg P, Rao GN. Corneal ulcer: diagnosis and management. Community Eye Health 1999; 12(30): 21-3. [PMID: 17491983]

[3] Srinivasan M, Gonzales CA, George C, et al. Epidemiology and aetiological diagnosis of corneal ulceration in Madurai, south India. $\mathrm{Br}$ J Ophthalmol 1997; 81(11): 965-71.

[http://dx.doi.org/10.1136/bjo.81.11.965] [PMID: 9505820]

[4] Sharma D, Mathur U, Gour A, Acharya M, Gupta N, Sapra N. Nocardia infection following intraocular surgery: Report of seven cases from a sankara eye hospital, Coimbatore. Indian J Ophthalmol 2017; 65(5): 371-5.

[http://dx.doi.org/10.4103/ijo.IJO 564 16] [PMID: 28573992]

[5] Chylack LT Jr, Leske MC, McCarthy D, Khu P, Kashiwagi T, Sperduto R. Lens opacities classification system II (LOCS II). Arch Ophthalmol 1989; 107(7): 991-7.

[http://dx.doi.org/10.1001/archopht.1989.01070020053028] [PMID: 2751471]

[6] Haripriya . Endophthalmitis reduction with intracameral moxifloxacin prophylaxis: Analysis of 600000 surgeries.Am Acad of Ophthal. 2017; 124: pp. 768-75.

[7] Galvis V, Tello A, Sánchez MA, Camacho PA. Cohort study of intracameral moxifloxacin in postoperative endophthalmitis prophylaxis. Ophthalmol Eye Dis 2014; 6: 1-4. [http://dx.doi.org/10.4137/OED.S13102] [PMID: 24526838] 
[8] Anand AR, Therese KL, Madhavan HN. Spectrum of aetiological agents of postoperative endophthalmitis and antibiotic susceptibility of bacterial isolates. Indian J Ophthalmol 2000; 48(2): 123-8. [PMID: 11116508]

[9] Bharathi MJ, Ramakrishnan R, Vasu S, Chirayath A, Palaniappan R. Nocardia asteroides keratitis in south India. Indian J Med Microbiol 2003; 21(1): 31-6.

[PMID: 17642971]

[10] Haripriya A, Lalitha P, Mathen M, et al. Nocardia endophthalmitis after cataract surgery: Clinicomicrobiological study. Am J Ophthalmol 2005; 139(5): 837-46.

[http://dx.doi.org/10.1016/j.ajo.2004.12.005] [PMID: 15860289]
[11] Mishra SK, Damodaran VN. Observations on the natural habitats of Cryptococcus neoformans and Nocardia asteroides. Indian J Chest Dis 1973; 15(4): 263-71.

[PMID: 4592588]

[12] Lovett IS, Houang ET, Burge S, et al. An outbreak of Nocardia asteroides infection in a renal transplant unit. Q J Med 1981; 50(198): 123-35.

[PMID: 7029599]

[13] Sridhar MS, Gopinathan U, Garg P, Sharma S, Rao GN. Ocular nocardia infections with special emphasis on the cornea. Surv Ophthalmol 2001; 45(5): 361-78.

[http://dx.doi.org/10.1016/S0039-6257(00)00207-1]

[PMID: $11274691]$

\section{(C) 2021 Kamath et al.}

This is an open access article distributed under the terms of the Creative Commons Attribution 4.0 International Public License (CC-BY 4.0), a copy of which is available at: (https://creativecommons.org/licenses/by/4.0/legalcode). This license permits unrestricted use, distribution, and reproduction in any medium, provided the original author and source are credited. 